\begin{tabular}{|c|c|c|}
\hline $\begin{array}{l}\text { PKS } \\
\text { PUBLIC } \\
\text { KNOLLEDGE } \\
\text { PROJECT }\end{array}$ & $\begin{array}{c}\text { REVISTA DE GEOGRAFIA } \\
\text { (RECIFE) } \\
\text { http://www.revista.ufpe.br/revistageografia }\end{array}$ & $\begin{array}{l}\text { OJS } \\
\frac{\text { OJEN }}{\text { OPOUNAL }} \\
\text { SYSTEMS }\end{array}$ \\
\hline
\end{tabular}

\title{
AVALIAÇÃO DA VULNERABILIDADE AMBIENTAL DE REGIÕES TROPICAIS MONTANHOSAS COM SUPORTE DE SIG
}

\author{
Braz Calderano Filho ${ }^{1}$, Helena Polivanov ${ }^{2}$, Waldir de Carvalho Junior ${ }^{3}$, Cesar da Silva \\ Chagas $^{4}$, Sebastião Barreiros Calderano ${ }^{5}$.
}

${ }^{1}$ Empresa Brasileira de Pesquisa Agropecuária.E-mail: braz.calderano@embrapa.br
${ }_{2}^{2}$ Universidade Federal do Rio de Janeiro.E-mail: hpolivanov@gmail.com
${ }^{3}$ Empresa Brasileira de Pesquisa Agropecuária.E-mail: waldir.carvalho@embrapa.br
${ }^{4}$ Empresa Brasileira de Pesquisa Agropecuária. E-mail: cesar.chagas@embrapa.br
${ }^{5}$ Empresa Brasileira de Pesquisa Agropecuária.E-mail: sebastião.calderano@embrapa.br

Artigo recebido em 17/01/2018 e aceito em 04/04/2018

\begin{abstract}
RESUMO
O objetivo do trabalho foi aplicar uma metodologia para estimar áreas propensas a vulnerabilidade ambiental na região serrana do estado do Rio de Janeiro, utilizando análise multicritério e modelagem em (SIG), através da álgebra de mapas. Os procedimentos utilizados envolveram a aquisição, conversão, armazenamento digital de dados básicos de solo, litologia, relevo, declive, uso da terra, vegetação e pluviosidade, confecção de base de dados, modelo digital de elevação e superposição temática em SIG, com base na interação, ponderação e atribuição de valores específicos a cada fator condicionante da vulnerabilidade, segundo a sua importância. Assim, cada fator foi ponderado do menos vulnerável (1), para o mais vulnerável (5). O mapa final resultante estratifica a área em oito classes de vulnerabilidade: baixa, baixa a moderada, moderada, alta, alta a muito alta, muito alta, muito alta a extremamente alta e extremamente alta. As áreas mais vulneráveis estão associadas a um conjunto de fatores que incluem rochas, relevos e solos mais instáveis, menor proteção da cobertura vegetal e precipitação mais elevada, as menos vulneráveis estão associadas a condições geoambientais inversas. Os resultados produzidos servem de instrumento auxiliar ao planejamento ambiental das terras de paisagens montanhosas da região serrana.
\end{abstract}

Palavras-chave: Gerenciamento das terras; Geoprocessamento; Álgebra de mapas; Modelo digital de elevação e Sistema de informação geográfica.

\section{VULNERABILITY ENVIRONMENTAL ASSESSMENT OF TROPICAL MOUNTAINOUS REGIONS BY USING GIS SUPPORT}

\begin{abstract}
This work aims at applying a methodology to estimate areas prone to environmental vulnerability located at the Rio de Janeiro mountainous region. The method consisted in using multi-criteria decision analysis and geographic information system (GIS) modeling through map algebra. The procedures used for the analysis included the acquisition, conversion and digital storing of basic data related to soil, lithology, relief, slope, vegetation, land use and precipitation. Added to these procedures there was also the creation of a database and a digital elevation and SIG thematic superposition model, based on the interaction, weighting and specific value attribution to each of the vulnerability conditioning factors. Thus, each factor was weighted from least vulnerable (1) to the most vulnerable (5). The final map shows a stratification of the area in eight vulnerability classes: low; low to moderate; moderate; high; high to very high; very high; very high to extremely high; and extremely high. The most vulnerable areas are associated with a set of factors comprising rocks, relief and soils that are more unstable, plus a lower protection of the land cover and an elevated precipitation. The least vulnerable areas occurs the inverse. This approach provides a tool to support environmental planning in mountainous areas.
\end{abstract}


Keywords: land management; geoprocessing; map algebra; digital elevation model and geographic information system.

\section{INTRODUÇÃO}

A região serrana do Estado do Rio de Janeiro, devido as suas características geoambientais apresenta tendência natural aos riscos ambientais, como deslizamentos, queda de blocos e movimentos de massa. Fatores que aliado às interferências das ações humanas na paisagem, conduzidas sem levar em consideração a importância da interação dinâmica existente entre os componentes da paisagem (solo, rocha, topografia, água e vegetação), acabam induzindo os riscos ao meio ambiente e as populações que habitam esses locais.

Os fenômenos naturais severos são influenciados pelas características do ambiente (rocha, solo, topografia, vegetação, condições meteorológicas), por sua vez, os desastres naturais ocorrem a partir da vulnerabilidade do ambiente, mas os danos ambientais são agravados com as ações antrópicas (KOBIYAMA 2006).

Na literatura atual encontram-se diferentes definições, enfoques e formas de análise da vulnerabilidade ambiental (BIRKMANN, 2007), exemplos são encontrados em Batjes \& Bridges (1997), FAO (2000), Kein (2001), Schoter et al. 2004, Zhong et al. (2005), Li et al. (2006), Metzger et al. 2006, e outros.

A avaliação da vulnerabilidade ambiental fornece um "status" da situação atual das terras, embora sua avaliação abrange a análise do potencial e riscos (BATJES \& BRIDGES, 1997), difere da avaliação de riscos que são previsões futuras (FAO, 2000).

Neste estudo, entende por vulnerabilidade ambiental os graus de tolerância do meio físico natural, ou o "status" de condições específicas dos ecossistemas ou segmentos da paisagem em análise, onde, a tolerância do meio (vulnerável ou estável) pode ter suas condições especificas de equilíbrio alteradas, ou por fatores de ordem natural ou provocadas pela interferência das ações humanas.

O conceito de vulnerabilidade envolve vários outros como o de fragilidade, sensibilidade, suscetibilidade, estabilidade, resiliência e resistência, em graus diferenciados dos componentes ambientais a determinado risco, proveniente de qualquer alteração em seu equilíbrio. A vulnerabilidade de uma região está relacionada com a natureza dos fatores que pressionam ou promovem mudanças ambientais, com o grau de sensibilidade do meio à essas mudanças e a sua capacidade regenerativa (METZGER et al 2006). Para Kruijf e Schouten (1987), vulnerabilidade é a incapacidade de lidar com fatores que causam stress, incluindo fatores naturais, baseando-se nas forças internas necessárias para que se mantenham as 
características essenciais do ecossistema, considerando-se os limites do mesmo.

A fragilidade pode ser entendida como a capacidade de resistir ou não as transformações e a sensibilidade é um conceito relacionado à capacidade amortizadora, onde a maior capacidade implica em menor sensibilidade. A resistência é o limite de capacidade que um sistema é capaz de resistir a influências externas, enquanto a resiliência é a aptidão de um determinado sistema que lhe permite recuperar o equilíbrio depois de ter sofrido uma perturbação. A resiliência refere-se à capacidade de um ecossistema reestabelecer seu ponto de equilíbrio, regenerando-se perante algum distúrbio (RICKLEFS, 2010 in SPINELLI et. al. 2017). É a capacidade de um sistema retornar a algum estado de referência após uma perturbação (SPINELLI et. al. 2017).

Nas últimas décadas houve um desenvolvimento muito rápido na aplicação de ferramentas digitais para a análise e avaliação de riscos ambientais (Van Westen et. al. 2008). Por outro lado, a evolução dos sistemas de informações geográficas (SIG) facilitaram a seleção e cruzamento de diferentes variáveis consideradas relevantes na análise ambiental, permitindo maior agilidade na integração de dados e na geração de resultados.

Nesse sentido, o objetivo deste trabalho foi aplicar uma metodologia para estimar áreas propensas a vulnerabilidade ambiental na região serrana do estado do Rio de Janeiro, utilizando análise multicritério e modelagem em (SIG), através da álgebra de mapas.

\section{MATERIAIS E MÉTODOS}

A área de estudo localizada na região serrana do estado do Rio de Janeiro, ocupa aproximadamente $468 \mathrm{~km}^{2}$ e abrange partes territoriais dos municípios de Nova Friburgo, Bom Jardim, Cordeiro, Trajano de Morais, Macuco, Casimiro de Abreu e Duas Barras.

A execução do trabalho envolveu a construção de um banco de dados digitais em SIG, aquisição, conversão e armazenamento de dados básicos em meio digital, manipulação de mapas temáticos e estimativa de áreas propensas a vulnerabilidade ambiental, com suporte de análise multicritério e álgebra de mapas, com base na interação e ponderação de fatores do meio físico condicionantes da vulnerabilidade ambiental.

A álgebra de mapas na análise espacial associa várias camadas e produz novos dados, a partir de operações aritméticas e funções de manipulação aplicadas a um ou mais mapas, obtendo resultados que permitem análises diversas (TOMLIN 1990). A análise multicritério baseia-se no mapeamento de variáveis por plano de informação, na definição do grau de pertinência de 
cada plano e de cada um de seus componentes de legenda, utilizando fatores de ponderação para a construção do resultado final (MOURA, 2007).

As informações temáticas de solos, geologia, relevo, uso e cobertura das terras, drenagem, vegetação, precipitação local, áreas sujeitas a inundação e suscetibilidade à erosão, necessários à avaliação foram extraídos dos estudos de Calderano Filho (2012) e Calderano Filho et al. (2012).

Foi organizado um banco de dados no ArcGIS 9.3, onde foi armazenado e padronizado os dados na projeção UTM, fuso 23S, Datum SIRGAS 2000, escala 1:50.000, efetuada a conversão de escalas e formatos vetoriais em matriciais, realizada a superposição dos temas, hierarquização de critérios e atribuição de pesos de importância.

A partir das feições digitalizadas, curvas de nível, limites, pontos cotados e hidrografia extraídas das cartas topográficas, na escala 1:50.000, folhas Quartéis, Cordeiro, Trajano de Morais, Duas Barras e Casimiro de Abreu, elaborou-se o modelo digital de elevação (MDE) da área, com resolução espacial de 30m, utilizando as ferramentas do SIG.

A partir da álgebra de mapas eliminou-se as depressões espúrias do MDE, produzindo em seguida, o mapa de declividade e outras variáveis morfométricas de interesse como direção do fluxo, fluxo acumulado, orientação e curvatura das vertentes. Estas informações associadas as informações temáticas armazenados no banco, auxiliaram na avaliação e estimativa da vulnerabilidade ambiental.

A avaliação da vulnerabilidade ambiental das terras é uma função dependente da análise integrada de uma complexidade de fatores interativos, tais como condições geológicas, pedológicas, geomorfológicas, geotécnicas, climáticas, hidrogeológicas e outros atributos inerentes aos fatores indicadores da vulnerabilidade, mais específicos à área em estudo, como condições topográficas do relevo, profundidade e textura dos solos, substratos, permeabilidade, drenabilidade, hidromorfismo, índices pluviométricos, entre outros. Estes fatores dependendo de suas condições atuais, influenciam mais ou menos na vulnerabilidade das terras (BATJES \& BRIDGES, 1997, FAO, 2000).

Os fatores preponderantes de maior peso, como condicionantes da vulnerabilidade na área de estudo, foram tipos de solos, tipos de rochas, declividade, formas do relevo e índices pluviométricos, estando os condicionantes uso e cobertura das terras em segundo plano, como fatores que podem induzir ou amenizar a degradação. Da mesma forma, as áreas de maior suscetibilidade à erosão ou sujeitas a inundação contribuem para incrementar a vulnerabilidade. Assim, esses fatores foram integrados combinando a análise multicritério 
com o método de álgebra de mapas, através da superposição temática em SIG e atribuição de pesos de importância a cada um dos fatores da análise, com valores específicos para cada parâmetro, segundo o grau de importância dos fatores em relação à vulnerabilidade ambiental.

\section{Critérios adotados para as variáveis condicionantes}

Os valores atribuídos a cada classe de um determinado tema (raster), considerando o grau de sensibilidade de cada unidade para o atributo selecionado, foram padronizados atribuindo-se um peso com números inteiros variando de 1 a 5 , que correspondem do mais baixo (1) ao mais alto (5), ou seja, quanto maior a nota mais vulnerável é o atributo. Após a atribuição do fator de escala para cada tema condicionante ele foi reclassificado nas cinco classes de vulnerabilidade e re-escalonado para valores de 0 a 255, de modo que 0 indica áreas menos vulneráveis e 255 mais vulneráveis. Esse procedimento foi aplicado a cada tema, conforme o potencial considerado. As classes de vulnerabilidade resultantes desta análise representam condições ambientais que apontam para diferentes fragilidades naturais. A tabela 1 mostra os valores atribuídos a cada classe de um determinado tema.

Tabela 1 - Critérios e pesos ponderados. Rio de Janeiro (2017).

\begin{tabular}{|c|c|c|c|c|c|}
\hline Critérios & Classes & Pesos & Critérios & Classes & Pesos \\
\hline \multirow{7}{*}{ 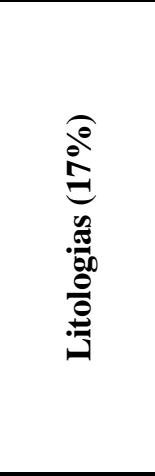 } & Gnaisse, leucognaisse & 5 & \multirow{7}{*}{$\begin{array}{l}\text { o̊ } \\
\stackrel{0}{0} \\
\frac{0}{0}\end{array}$} & Cambissolo haplico e húmico & 5 \\
\hline & Depósitos de talus & 5 & & Neossolo litólico & 5 \\
\hline & Ortognaisse, granodioríto & 4 & & $\begin{array}{l}\text { Argissolo (vermeho e vermelho } \\
\text { amarelo) }\end{array}$ & 4 \\
\hline & Migmatitos & 3 & & Latossolo amarelo ácrico húmico & 4 \\
\hline & Granito, gabro & 3 & & $\begin{array}{l}\text { Latossolo (amarelo, vermelho e } \\
\text { vermelho-amarelo) }\end{array}$ & 3 \\
\hline & Depósitos coluvionares & 5 & & $\begin{array}{l}\text { Cambissolo flúvico, Neossolo } \\
\text { flúvico e Gleissolo }\end{array}$ & 2 \\
\hline & Planícies aluvionares & 1 & & $\begin{array}{l}\text { Tipo de terreno (afloramento } \\
\text { de rocha sem recobrimento**) }\end{array}$ & 1 \\
\hline \multirow{7}{*}{ 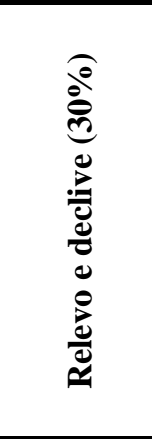 } & Escarpado $(>75 \%)$ & 5 & \multirow{7}{*}{ 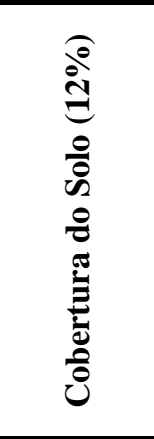 } & $\begin{array}{c}\text { Cultivos sem práticas } \\
\text { conservacionistas }\end{array}$ & 5 \\
\hline & Montanhoso (45 a $75 \%$ ) & 5 & & Solo exposto & 5 \\
\hline & Forte Ondulado (20 a 45\%) & 4 & & $\begin{array}{l}\text { Culturas de ciclo longo, } \\
\text { Silvicultura e plantio de Café }\end{array}$ & 4 \\
\hline & Ondulado (14 a 20\%) & 3 & & Pastagens; mineração & 3 \\
\hline & $\begin{array}{l}\text { Moderadamente } \\
\text { Ondulado (8 a } 14 \%)\end{array}$ & 2 & & Floresta e capoeira densa & 2 \\
\hline & Suave Ondulado (3 a 8\%) & 1 & & Corpos Dágua & 1 \\
\hline & Plano (0 a 3\%) & 0 & & Área urbana & 0 \\
\hline \multirow{5}{*}{ 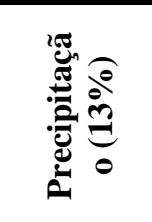 } & $>1500 \mathrm{~mm}$ & 5 & \multirow{5}{*}{ 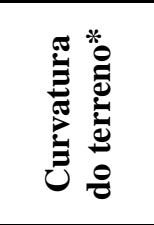 } & Muito Côncavo & 5 \\
\hline & $1350 \mathrm{~mm}$ a $1500 \mathrm{~mm}$ & 4 & & Côncavo & 4 \\
\hline & $1250 \mathrm{~mm}$ a $1350 \mathrm{~mm}$ & 3 & & Muito convexo & 3 \\
\hline & $1100 \mathrm{~mm}$ a $1250 \mathrm{~mm}$ & 2 & & convexo & 2 \\
\hline & $<1100 \mathrm{~mm}$ & 1 & & plano & 1 \\
\hline
\end{tabular}




\begin{tabular}{|c|c|c|c|c|c|}
\hline \multirow{6}{*}{ 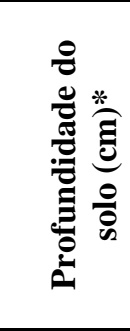 } & $<50-100$ (Raso) & 5 & \multirow{6}{*}{ 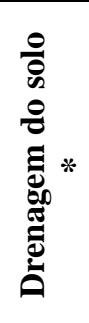 } & Mal e muito mal drenado & 5 \\
\hline & 50 - 100 (Pouco Profundo) & 4 & & Imperfeitamente drenado & 5 \\
\hline & $150-200$ (Profundo) & 2 & & Moderadamente drenado & 4 \\
\hline & $>200$ (Muito Profundo) & 1 & & Bem drenado & 3 \\
\hline & & & & Acentuadamente drenado & 2 \\
\hline & & & & $\begin{array}{l}\text { Excessivamente e fortemente } \\
\text { drenado }\end{array}$ & 1 \\
\hline \multirow{5}{*}{ 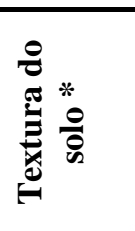 } & Arenosa, Arenosa / média & 5 & & & \\
\hline & Média & 4 & & & \\
\hline & Média/argilosa & 3 & & & \\
\hline & Argilosa & 2 & & & \\
\hline & Muito Argilosa & $\overline{1}$ & & & \\
\hline
\end{tabular}

Fonte: Elaborado pelos autores.

\section{Estabelecimento de critérios e classes por tema}

\section{Litologias predominantes}

$\mathrm{Na}$ análise do grau de fragilidade litológica considerou o grau de coesão dos minerais em cada unidade mapeada, conforme utilizado por Crepani et al. (2001). Os tipos de rochas dominantes, teve por base o mapa de Matos et al. (1982), ajustado para a escala de 1:50.000. Assim quanto mais antiga a idade da rocha e maior o grau de coesão dos minerais, menor valor foi atribuído à vulnerabilidade da unidade.

Predominam na área rochas pertencentes ao Complexo Rio Negro (ortognaisses e migmatitos), associados a rochas do Batólito Serra dos Órgãos (ortognaisses granodioríticos), intercaladas a faixas de gnaisses paraderivados do Grupo Paraíba do Sul (leucognaisses e rochas metassedimentares) e rochas ígneas de composição granodiorítica a granítica, mais raramente gabróica, que intrudiram estas unidades. Em menor extensão, ocorrem terrenos do Quaternário representados pelos depósitos aluviais inconsolidados de consistência arenoargilosa, argilosa e silto-argilosa.

As unidades granitos, migmatitos e ortognaisses receberam notas melhores que os depósitos de colúvio, depósitos de tálus e planícies aluvionares, conforme legenda do mapa litológico disponível em Matos et al. (1982). Após essa etapa o mapa litológico foi agrupado e reclassificado nas cinco classes de vulnerabilidade e reescalonado para valores de 0 a 255 . Este procedimento foi repetido para cada tema subsequente, em cada variável condicionante.

\section{Tipos de solos predominantes}

Considerou-se o grau de desenvolvimento dos solos, textura dos solos, estrutura, profundidade efetiva, porosidade, permeabilidade, densidade do solo, teor de matéria orgânica e drenagem interna. Características essas, relacionadas com o potencial e predisposição dos terrenos aos processos de erosão, movimentos de massa e escorregamentos superficiais. 
Com relação à condição de drenagem dos solos de baixada, foi considerada a permeabilidade, a qual depende de sua textura, teor de matéria orgânica, tipo de argila, tipo de estrutura, camada cimentada e/ou de impedimento, além da altura do lençol freático e o risco de inundação devido a proximidade de rios, córregos e lagos.

O mapa de solos de Calderano Filho et al. (2012), é composto por diferentes associações com unidades taxonômicas simples ou compostas por dois ou mais componentes. O critério estabelecido foi a ponderação de cada componente de acordo com a sua contribuição na composição da unidade de mapeamento de solos. No caso de uma única classe componente da legenda adotou-se $100 \%$ do valor de "1" a "5", nas associações adotou o percentual de participação do componente sobre o valor de "1" a "5". Após essa etapa o mapa de solos foi agrupado nas principais classes de solos dominantes na área, sendo elas: Argissolo Vermelho Amarelo (PVA), Argissolo Vermelho (PV), Argissolo Amarelo (PA), Latossolo Vermelho (LV), Latossolo Vermelho Amarelo (LVA), Latossolo Amarelo (LA), Latossolo Amarelo Ácrico (LAw), Cambissolo Háplico (CX), Cambissolo Húmico (CH), Neossolo Litólico (RL), Neossolo Flúvico (RY) e Cambissolo Flúvico (CY), esses dois últimos restritos as áreas de baixada.

\section{Uso e cobertura das terras}

A cobertura do solo funciona como facilitadora ou amortecedora da fragilidade das terras. Para cada uso da terra encontrado na área, conforme Calderano Filho (2012), foi estabelecido o grau de vulnerabilidade, levando em consideração o papel da vegetação como manto protetor da paisagem e sua capacidade de amenizar a ação das águas, conjugado com os demais critérios considerados.

Foram adotados os valores mais baixos, entre 1 e 3 para os terrenos protegidos que apresentam maior densidade da cobertura vegetal, enquanto os terrenos com coberturas herbáceas ou gramíneas, com culturas de ciclos curtos ou expostos receberam valores elevados entre "4" e " 5 ", considerando a baixa densidade de cobertura.

\section{Precipitação}

Como forma de diferenciar o efeito da sazonalidade e intensidade da precipitação, baseou-se nas séries históricas de 1966 a 2007, das estações pluviométricas existentes na área (AGÊNCIA NACIONAL DE ÁGUAS, 2007). A precipitação é um índice que variou entre 1100 a 1600 mm, por sub-bacias hidrográficas, para as estações de Bom Jardim, Barra Alegre, Vargem Alta, Ponte Bersort e Dona Mariana.

Os totais pluviométricos elevam ou diminui o grau de vulnerabilidade, quanto maior o índice 
de precipitação maior a exposição da área a erosão e a outros riscos ambientais, tal fato é acentuado quando não há cobertura vegetal sobre o solo. Foi atribuído o valor 1 (baixo) para as áreas com precipitação entre 1100 e 1200 mm de chuva, e valor 5 (muito alto) para áreas com precipitação superior a $1600 \mathrm{~mm}$.

\section{Relevo e declividade}

O relevo tem importância nos processos geodinâmicos, principalmente por ser a declividade o fator responsável pela maior ou menor infiltração das águas das chuvas e velocidade de escoamento das águas, sendo um dos principais fatores na análise de riscos a deslizamento de terra. A geração do modelo digital da elevação e do mapa de declividade desempenharam funções importantes, particularmente na análise das formas de relevo, amplitudes altimétricas e declividades. O detalhamento das formas de relevo se deu junto ao processamento das variáveis geomorfométricas (declividade, curvatura vertical e curvatura horizontal).

Compartimentou-se o relevo da área em sete classes de declividade, ou seja, A (0-3\%) relevo plano, B (3-8\%) relevo suave ondulado, C (8-14\%) relevo moderadamente ondulado, D (14$20 \%$ ) relevo ondulado, E (20-45\%) relevo forte ondulado, F (45-75\%) relevo montanhoso e G (acima de 75\%) relevo escarpado. Agrupando em seguida as classes montanhoso e escarpado, devido à falta de representação cartográfica na escala de trabalho adotada. Os intervalos de classes de declividade utilizados estão de acordo com Wintter et al. (1990).

\section{Drenagem interna}

O volume de água no solo tem relações com a suscetibilidade das terras à erosão, deslizamentos e movimentos de massa. Considerando que uma melhor condição de drenagem do solo favorece o melhor desenvolvimento das plantas, e consequentemente o desenvolvimento de uma melhor cobertura do solo. Estabeleceu-se as classes de drenagem utilizando a nomenclatura sugerida em Embrapa (2006), e apoio na interpretação das informações temáticas de solos, drenagem e áreas sujeitas a inundação.

\section{Potencial de erodibilidade dos solos}

Foi inserido na avaliação da vulnerabilidade das terras, o potencial de susceptibilidade dos solos à erosão. Entende-se que as áreas mais propensas à erosão são mais vulneráveis que outras áreas mais estáveis do ponto de vista geotécnico.

Para a avaliação do potencial erosivo das terras gerou-se o fator LS, conforme a equação de Hengel (2004), que associado com parâmetros e atributos de clima, solos, geologia, relevo e vegetação, após etapas de cruzamento no SIG, possibilitou a criação de um mapa com as classes de suscetibilidade das terras à erosão superficial. Os graus de erosão considerados de 
forma a coincidir com as classes de declividade da área foram: Nulo $(<3 \%)$, Ligeiro $(3 \%$ a $8 \%$.), Ligeiro a Moderado (8\% a $14 \%)$, Moderado a forte (14\% a $20 \%$.), Forte $(20 \%$ a $45 \%$.), Muito forte a Extremamente Forte ( $>45 \%$ ).

Integração dos dados e avaliação da vulnerabilidade

Nos locais onde ocorrem situações de relacionamentos entre extremos de vulnerabilidade segundo a declividade, com extremos de vulnerabilidade segundo fatores pedológicos, o uso e cobertura da terra aliado às características do solo, como drenagem, rochosidade, pedregosidade e vegetação atual funcionou como mecanismo de compensação. Os totais pluviométricos podem elevar ou diminuir o grau de vulnerabilidade, enquanto a vegetação pode funcionar como efeito protetor e capacidade de amortizar ou amenizar a ação das águas. Após a padronização das variáveis utilizadas, caracterização dos graus de pertinência, atribuição de pesos e notas para cada componente de legenda, os dados foram processados no SIG. A integração das variáveis condicionantes foi realizada através da álgebra de mapas, após sucessivas etapas, primeiro para integrar os dados de cada variável condicionante no SIG, e posteriormente para o cruzamento entre as variáveis. O fator de participação de cada variável condicionante na análise pode ser observado na equação 1 .

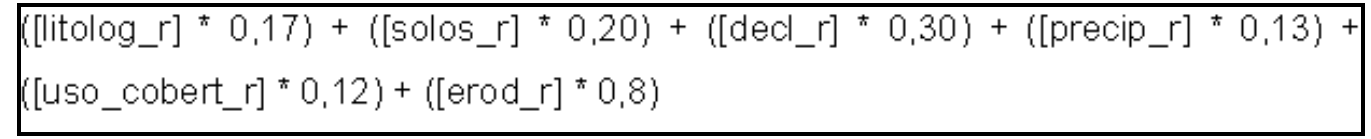

Para reclassificar as variáveis a serem trabalhadas no SIG, foram inseridos os shapefiles de cada variável, e para cada arquivo vetorial criou-se um arquivo raster. Para reclassificar os valores dos componentes de cada legenda já no formato raster, combinar as variáveis e gerar a espacialização de áreas vulneráveis, utilizou-se as funções do SIG.

Esses procedimentos permitiram o cruzamento ponderado dos fatores analisados, as relações entre eles e a sobreposição e atribuição dos valores das classes de vulnerabilidade. Assim, diversos ensaios foram efetuados variando os pesos e graus de ponderação entre os fatores envolvidos, gerando três diferentes cenários de vulnerabilidade.

Os mapas gerados com valores entre 0 e 255, foram estratificados a principio em 5 classes básicas de vulnerabilidade ambiental, sendo elas Baixa (B), Moderada (M), Alta (A), Muito Alta (MA) e Extremamente Alta (EA). Na etapa de campo para verificação, ajustes e validação da modelagem efetuada, o mapa selecionado foi ajustado a realidade de campo e reclassificado em 8 classes de vulnerabilidade ambiental, sendo elas: Baixa (B), Baixa a Moderada (B/M), Moderada (M), Alta (A), Alta a Muito Alta (A/AM), Muito Alta (MA), Muito Alta a Extremamente Alta (MA/EA) e Extremamente Alta (EA). A Figura 1, mostra a 
matriz de estabilidade e vulnerabilidade das terras.

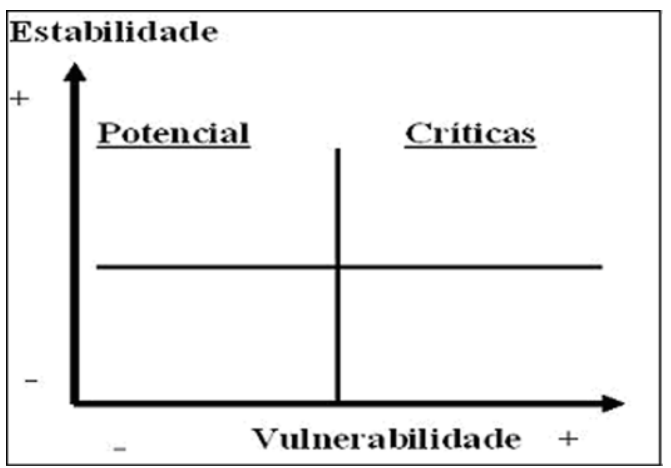

Fonte: Adptado de Becker \& Egler (1996).

Fig. 1 - Matriz de estabilidade e vulnerabilidade das terras.

Nesse sentido, quanto mais baixa a classe de vulnerabilidade assinalada no mapa, mais alta será a estabilidade do ambiente onde se insere, conforme mostra a Figura 1.

\section{RESULTADOS}

A área de estudo apresenta variabilidade nas características geológicas, geomorfológicas e pedológicas e abrange os dois principais domínios fisiográficos regionais, as terras altas e baixas. O elevado potencial de fragilidade e vulnerabilidade de suas terras aos riscos ambientais, como movimentos de massa, escorregamentos e erosão acelerada dos solos, se deve principalmente as características topográficas do relevo montanhoso, associado aos índices de precipitação e às demais condicionantes geoambientais locais. Em geral, os terrenos mais íngremes preservam a cobertura florestal, atenuando um pouco a instabilidade da área, mas as interferências antrópicas na paisagem potencializam os riscos ambientais.

Através da análise conjunta das diversas condicionantes do meio físico que integram a paisagem local, das informações contidas no banco de dados e da literatura consultada, os vários ambientes que compõem a paisagem local foram agrupados para efeitos de apresentação dos resultados, em quatro feições geomorfológicas simplificadas, ou seja, as serras alinhadas, onde se incluem as porções mais elevadas e íngremes da paisagem; colinas e morros com encostas forte onduladas e montanhosas; colinas e morros com encostas onduladas, suave onduladas e inclusões de forte onduladas e as áreas aplainadas, onde se incluem as baixadas (planícies fluviais), áreas de terraços e áreas suavizadas na paisagem de alvéolos intermontanos.

Estas feições se inserem nas duas unidades definidas em (Dantas 2001), de domínio de morros elevados e domínio montanhoso, com ocorrência de alvéolos de relevo suave, 
subordinados ao domínio montanhoso.

A Figura 2 mostra o mapa com a distribuição espacial das classes de vulnerabilidade ambiental.

As tabelas 2 e 3 mostram a área e os percentuais de ocorrência das classes de vulnerabilidade e de relevo que ocorrem na área.

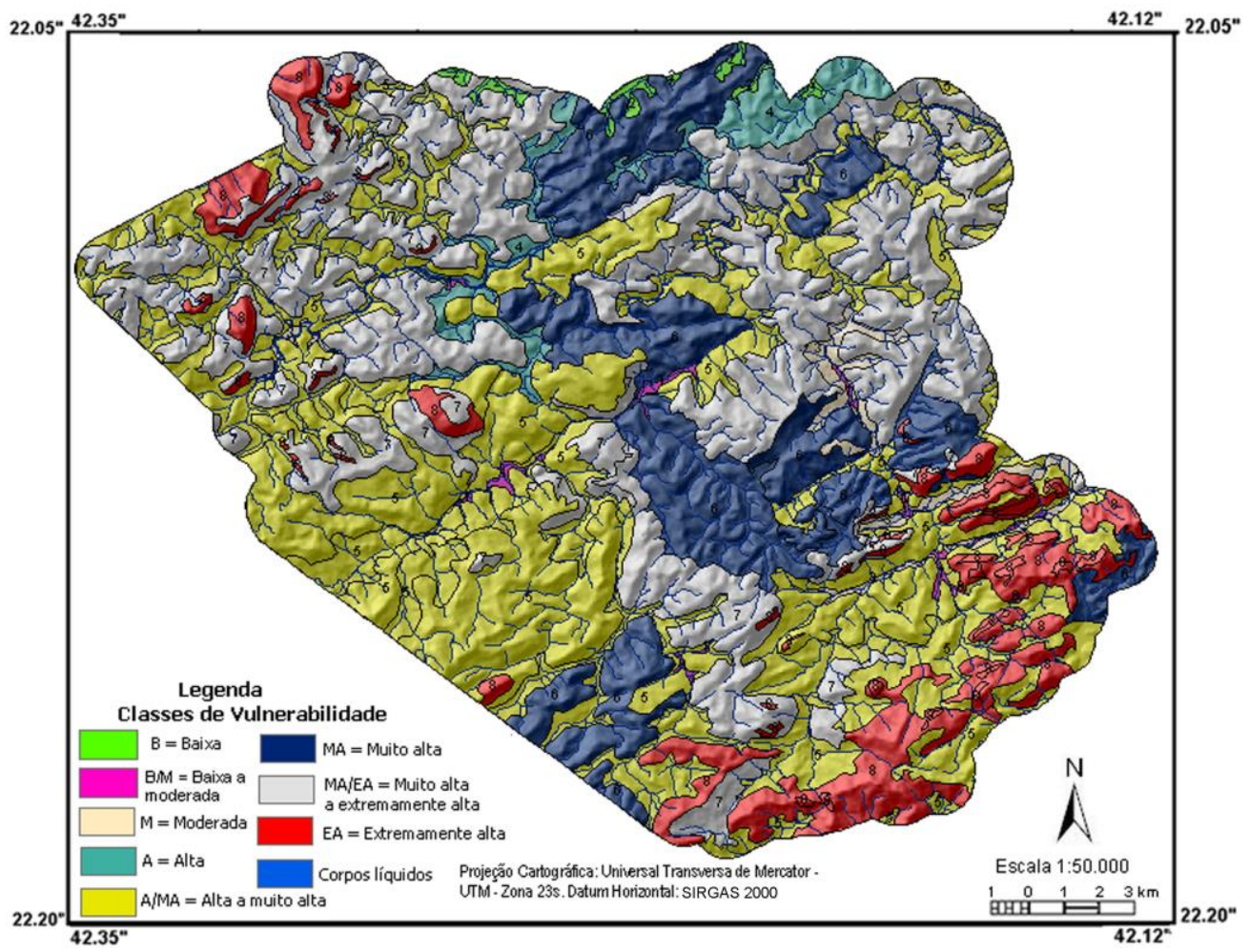

Fonte: Elaborado pelos autores.

Figura 2 - Distribuição espacial das classes de vulnerabilidade ambiental. Rio de Janeiro (2017).

Tabela 2 - Distribuição das classes vulnerabilidade ambiental.Rio de Janeiro (2017).

\begin{tabular}{|l|c|c|c|}
\hline \multicolumn{1}{|c|}{ Vulnerabilidade } & Classe & Área (ha) & \% \\
\hline Baixa (B) & 1 & 284,05 & 0,58 \\
\hline Baixa a Moderada (B/M) & 2 & 247,38 & 0,51 \\
\hline Moderada (M) & 3 & 783,20 & 1,62 \\
\hline Alta (A) & 4 & $1.558,47$ & 3,22 \\
\hline Alta a Muito Alta (A/MA) & 5 & $18.426,11$ & 38,01 \\
\hline Muito Alta (MA) & 6 & $7.495,93$ & 15,48 \\
\hline Muito Alta a Extremamnete Alta (MA/EA) & 7 & $15.091,1$ & 31,13 \\
\hline Extremamente alta (EA) & 8 & $4.567,57$ & 9,42 \\
\hline Água & & 15,24 & 0,03 \\
\hline
\end{tabular}




\begin{tabular}{|c|c|c|c|}
\hline Total & & $48.469,00$ & 100,00 \\
\hline
\end{tabular}

Fonte: Elaborado pelos autores.

Tabela 3 - Distribuição das classes de relevo. Rio de Janeiro (2017).

\begin{tabular}{|c|c|c|}
\hline Classe de relevo & área (ha) & \% \\
\hline Plano & 862,74 & 1,78 \\
\hline suave ondulado & $3.950,22$ & 8,15 \\
\hline Ondulado & $10.096,10$ & 20,83 \\
\hline forte ondulado & $20.841,69$ & 43,00 \\
\hline Montanhoso & $9.703,50$ & 20,02 \\
\hline Escarpado & $3.014,77$ & 6,22 \\
\hline Total & $48.469,06$ & 100,00 \\
\hline
\end{tabular}

Fonte: Elaborado pelos autores.

As feições geomorfológicas estabelecidas para a área em estudo são apresentadas abaixo.

Feição 1 - Corresponde às porções mais elevadas e íngremes da paisagem (altos das serras, topos dos divisores de água), de relevo montanhoso e escarpado, com blocos rochosos salientes, escarpas e encostas íngremes. Apresentam vulnerabilidade extremamente alta, condicionada por relevo e declividade acentuada, profundidade dos solos e rochosidade abundante. É constituída por rochas ígneas e metamórficas (granitos, migmatitos e ortognaisse), onde predominam Neossolo Litólico e Cambissolo háplico, distróficos, de textura argilosa ou média/argilosa. Seguidos de Cambissolo húmico e Argissolo Vermelho Amarelo distrófico, de textura argilosa ou muito argilosa, Latossolo Amarelo ácrico e distrófico, húmicos, de textura argilosa (CALDERANO FILHO et al. 2012). São de profundidade variada, permeáveis, bem a acentuadamente drenados. Nesta unidade os ambientes se distinguem entre floresta tropical perenifólia e subperenifólia, com aspecto de pouco alterada, manchas de floresta rala e ocorrência de vegetação rupestre de pouca expressão cartográfica.

São glebas de muito forte a extremamente forte susceptibilidade dos solos à erosão, susceptíveis a escorregamentos, movimentos de massa e queda de blocos. A impermeabilidade do material rochoso, associado aos solos menos profundos e vegetação pouco densa, incrementa os processos erosivos nestes locais. As rochas desta unidade são de maior resistência às alterações, mas quando associadas as altas declividades, solos menos espessos e pluviosidade mais elevada, passam a compor glebas de vulnerabilidade ambiental extremamente alta. Portanto, recomenda-se manter o solo sempre coberto nesta feição.

Feição 2 - Corresponde às colinas e morros com encostas do cristalino forte onduladas e montanhosas circundadas por exposição rochosa. Apresentam vulnerabilidade muito alta a extremamente alta, condicionada por relevo e declividade, espessura do solo e rochosidade 
abundante. Compreende terras com vertentes íngremes e afloramentos rochosos. Onde predominam Latossolo Amarelo distrófico típico ou húmico, Latossolo Vermelho - Amarelo distrófico típico, de textura argilosa ou muito argilosa e Cambissolo háplico e húmico, de textura argilosa ou média/argilosa que ocorrem associados à afloramentos de rocha (CALDERANO FILHO et al. 2012). Eventualmente ocorrem Argissolo Vermelho-Amarelo distrófico típico, latossólico ou câmbico, de textura média e argilosa.

Os solos são permeáveis, profundos a pouco profundos, bem a acentuadamente drenados. Onde, os solos são menos profundos, podem ocorrer matacões e afloramentos de rocha. Estas terras apresentam muito forte a extremamente forte susceptibilidade à erosão, sujeitas a movimentos de massa e queda de blocos. Encontram-se ocupadas com pastagem, campo rupestre, floresta rala sob afloramentos e floresta natural, com predomínio de floresta tropical subperenifólia. A concentração e os índices de precipitação incrementam os riscos ambientais, caso mantenha-se o solo descoberto, ou seja retirada a cobertura vegetal nessa unidade.

Feição 3 - Corresponde às posições intermediárias de colinas e morros com encostas onduladas, suave onduladas e inclusões de forte onduladas. Apresentam vulnerabilidade desde moderada até alta e muito alta, condicionada por relevo, declividade, textura dos solos, ligeira rochosidade, moderada pedrogosidade e índices pluviométricos.

Compreende as elevações com menor altitude do que as serras e poucas ocorrências de afloramentos de rochas, inseridas nas encostas íngremes do cristalino, de relevo ondulado e forte ondulado, onde se incluem pequenas áreas de depósito de tálus. Os solos de maior ocorrência são Latossolo Vermelho, Latossolo Vermelho-Amarelo e Latossolo Amarelo, distróficos típicos, de textura argilosa ou muito argilosa, seguidos de Argissolo Vermelho Amarelo, distrófico típico ou latossólico (CALDERANO FILHO 2012, CALDERANO FILHO et al. 2012). Em menor proporção ocorrem Argissolos Vermelho Amarelo e Amarelos distróficos típicos, Latossolo Amarelo distrófico húmico e inclusão de Cambissolo háplico, textura argilosa ou média/argilosa. Na classe dos argissolos ocorrem solos de textura média/argilosa, média/muito argilosa ou argilosa/muito argilosa.

Os solos são de profundidade variada, permeáveis, bem a acentuadamente drenados e de baixa fertilidade natural. Nas áreas de solos menos profundos, podem ocorrer matacões e afloramentos de rocha e áreas de depósito de tálus. Estas terras apresentam susceptibilidade à erosão desde moderada até muito forte. O uso agrícola é com pastagens, plantios de olerícolas, café, construções civis, capoeiras em estágio de regeneração e pequenas áreas de floresta subperenifólia (CALDERANO FILHO 2012). 
A posição na paisagem, o relevo forte ondulado, ocorrência de solos de textura média/ argilosa, a suscetibilidade muito forte dos solos à erosão e os índices de precipitação, conferem um maior grau de fragilidade, a certas glebas dessa unidade. O principal risco desta feição é com a erosão acelerada dos solos e perda do horizonte A, e em certos locais, ravinamentos e até movimentos de massa de certa amplitude. Recomenda-se manter o solo coberto, não retirar a cobertura vegetal, ou fazer desmatamentos generalizados e cortes de estradas planejados de forma inadequada.

Feição 4 - Corresponde às áreas aplainadas, onde se incluem as baixadas (planícies fluviais), áreas de terraços e áreas suavisadas na paisagem de alvéolos intermontanos. Abrange as classes de vulnerabilidade baixa e baixa a moderada.

A classe de vulnerabilidade baixa compreende parte das terras baixas suavizadas, onde se inclui áreas de alvéolos intermontanos, entulhadas por material deposicional, com menor umidade e sujeitas a menores riscos de inundações que as áreas planas de várzeas. São áreas com declives inferiores a 8\%, caracterizadas como áreas de recepção dos movimentos de massa das partes elevadas. Ocorrem ora margeando a planície de inundação do rio Grande, ora constrita entre as elevações coluviais. Nas áreas suavizadas e de alvéolos predominam Latossolo Amarelo, Latossolo Vermelho Amarelo e Argissolo Amarelo, distróficos típicos, de textura argilosa ou muito argilosa (CALDERANO FILHO 2012, CALDERANO FILHO et al. 2012), desenvolvidos de material coluvial, sob vegetação de floresta tropical subperenifólia.

Nas áreas de várzeas predominam Neossolos Flúvicos distróficos, que ocorrem associados à Cambissolos Flúvicos e inclusão de Gleissolos Háplicos, sob vegetação de floresta tropical subperenifólia de várzea, desenvolvidos de material sedimentar diverso. Os solos são de profundidades variadas e drenagem imperfeita em certos locais.

O risco ocasional de inundação, presença do lençol freático próximo a superfície e possibilidade de contaminação de corpos d'água, por agrotóxicos ou por dejetos humanos e de animais, são as principais limitações nas áreas de várzeas.

A classe de vulnerabilidade moderada compreende apenas as áreas planas de várzeas, com declives inferiores a 3\%, difere da classe anterior por apresentar maiores riscos de inundação, devido ao nível do lençol freático próximo a superfície em algumas épocas do ano. São terras pouco suscetíveis à erosão, com limitações por excesso de água e deficiência de aeração, propícias a sofrer inundações periódicas.

De acordo com os critérios adotados que considera a integração entre as variáveis condicionantes, as distintas pontuações e sua influência no resultado final, constata-se que 
variáveis que receberam pontuação de baixo grau de vulnerabilidade de forma isolada, quando conjugadas com as demais características de outras variáveis condicionantes com grau superior, passam a compor glebas de maior potencial de instabilidade, passíveis de sofrerem riscos futuros. Como é o caso de rochas ígneas que de forma isolada são mais estáveis, mas ao associar-se à vegetação pouco densa, às áreas íngremes da paisagem e aos solos mais frágeis, incrementa os riscos ambientais e potencializa os processos erosivos nestes locais.

As rochas que receberam baixo grau de vulnerabilidade foram os granitos, ortognaisses, peguimatitos e migmatitos. Os gnaisses receberam grau intermediário por apresentarem condições mais favoráveis ao intemperismo e maior instabilidade quando recortadas para a instalação de estradas vicinais e outras intervenções antrópicas na paisagem.

Os depósitos coluvionares e de tálus, receberam grau elevado de vulnerabilidade por serem áreas de maior instabilidade. Os depósitos sedimentares (associados aos cursos d’água), receberam grau moderado devido ao baixo potencial de infiltração dos solos que aí ocorrem, parcialmente saturados de água e o risco ocasional de inundação.

Para o relevo as colinas suaves e onduladas com declividades inferiores a 14\%, receberam pontuação baixa por serem glebas de menores riscos, baixo potencial de instabilidade e baixo grau de vulnerabilidade. Relevos de colinas e morros com declividades entre $14 \%$ a $30 \%$, foram considerados áreas de moderada a alta vulnerabilidade quando comparados com outros tipos de relevo encontrados na região. Os relevos de morros com encostas íngremes e declividades entre $20 \%$ a $30 \%$, receberam uma maior pontuação devido a essas condições favorecerem o escoamento superficial em detrimento dos processos de infiltração, potencializando os processos erosivos associados.

As serras, escarpas e encostas íngremes foram agrupadas em uma única unidade com declividades superiores a 30\%, recebendo pontuação elevada, devido a essas condições potencializar os processos erosivos associados, escorregamentos e movimentos de massa. Nestas áreas a instabilidade do ambiente é maior quando ocorre intervenções antrópicas na paisagem, como a remoção da cobertura vegetal, abertura de estradas vicinais, preparo do solo para plantios e construções civis. As áreas de planícies aluviais receberam pontuação mais elevada por serem propícias a inundações e acumulação de clásticos.

No atributo solo considerou-se os tipos de solos dominantes agrupados por classes, prevalecendo a noção que quanto mais desenvolvido, profundo e homogêneo é o solo, mais estável é a área do ponto de vista dos riscos ambientais e mais apropriado seria o solo para suportar as intervenções antrópicas. 
Os latossolos por serem bem desenvolvidos, profundos, bem formados, possuírem boa drenagem interna e baixas condições de suscetibilidade erosiva foram bem avaliados. Seguidos dos argissolos bem desenvolvidos, profundos e com textura mais homogênea no perfil de solo. Os argissolos com textura binária e mais argilosos no horizonte $\mathrm{B}$, condições que dificultam a drenagem interna para os níveis inferiores, favorecendo a movimentação e escorregamento da camada superior, receberam avaliação inferior aos demais. Fato já constatado por Bigarella et al. (2003).

Os cambissolos ao contrário dos latossolos e argissolos, possuem horizonte B incipiente e elevado potencial de erodibilidade. Os cambissolos húmicos receberam pontuação um pouco melhor que os cambissolos háplicos, devido à presença de maior conteúdo de matéria orgânica, que funciona como uma proteção aos processos erosivos superficiais. Os cambissolos de uma maneira geral, estão associados a relevos normalmente íngremes e são considerados mais instáveis perante as intervenções antrópicas.

Da mesma forma que os cambissolos háplicos, os neossolo litólicos por serem solos pouco profundos, menos estáveis, com potencial elevado de erodibilidade e ocorrerem em posições da paisagem consideradas delicadas foram classificados como mais instáveis e de alto risco. Os neossolos flúvicos e cambissolo flúvicos (solos restritos as áreas de baixadas e de várzeas) receberam grau moderado devido às baixas condições de infiltração, fatos que os tornam propícios a sofrerem inundações periódicas.

O mapa de vulnerabilidade natural produzido com valores entre 0 e 25 foi estratificado a princípio em cinco classes de vulnerabilidade, passou por um segundo cruzamento com base nos ajustes de campo e dados de uso e ocupação das terras, resultando no mapa de vulnerabilidade ambiental da área com oito classes, como mostra a figura 2. Houve necessidade de criar classes intermediárias devido as características geoambientais da área e a inclusão de segmentos da paisagem com vulnerabilidade incoerente com a classe delimitada na primeira estratificação. $\mathrm{O}$ mapa resultante figura 2 , demonstrou coerência com a realidade de campo na área de estudo, os maiores níveis de vulnerabilidade concentraram principalmente nas altitudes e declividades mais elevadas, vertentes côncavas, em terrenos com solos mais rasos, solos com maior teor de argila no horizonte $\mathrm{B}$, áreas onde a cobertura vegetal é deficitária ou pouco densa e áreas de afloramentos rochosos.

As áreas de maior instabilidade e alta potencialidade aos riscos ambientais correspondem às feições geomorfológicas 1 e 2, acima descritas. São áreas mais instáveis de relevo montanhoso e escarpado que se associam à rochas ígneas e metamórficas, e predomínio de 
solos pouco profundos. São setores da paisagem de maior instabilidade, onde as declividades somadas ao escoamento superficial mais rápido favorecem a erosão dos solos, transporte de blocos de rochas e matacões, principalmente face as intervenções antrópicas na paisagem, como cortes para a instalação de estradas vicinais, construções civis e implantação de atividades agrícolas.

As áreas de média potencialidade aos riscos ambientais correspondem à feição 3 e partes da feição 2. São glebas onde se associam relevos de morros, rochas metamórficas e predomínio de solos profundos. Grande parte dessas glebas encontram-se ocupadas por pastagens mal manejadas e fragmentos descontínuos de floresta natural (CALDERANO FILHO 2012). A associação entre relevos de morros suaves, rochas resistentes (ortognaisse) e solos mais profundos, contribuem para o equilíbrio da dinâmica do meio físico. Devido a indisponibilidade de terrenos compatíveis para o crescimento das cidades e núcleos rurais, estas áreas representam a única alternativa para a expansão urbana na região serrana.

As áreas de baixa potencialidade aos riscos ambientais corresponde à feição 4, onde duas situações distintas foram descritas; as áreas de terraços e alvéolos intermontanos e as áreas de baixadas (planícies fluviais). Nas áreas de alvéolos a associação entre relevos suaves, presença de solos com boas condições de profundidade, textura e baixo potencial para erosão, favorecem a instalação e expansão dos núcleos urbanos locais.

Fato constatado por Dantas (2001). As áreas não recomendadas desta feição, correspondem às regiões de várzea com nível do lençol freático próximo à superfície e passíveis de sofrerem risco ocasional de inundação.

\section{CONCLUSÕES}

A metodologia utilizada com base na interação e ponderação de fatores do meio físico condicionantes da vulnerabilidade, mostrou-se adequada ao estudo do tema, alcançando resultados coerentes com a realidade local, pois, onde foram identificados à ocorrência de compartimentos mais frágeis e problemáticos em função da litologia, relevo, profundidade dos solos, gradiente textural, maior declividade, índices pluviométricos e menor grau de cobertura vegetal, estes se encaixaram nas classes de vulnerabilidade alta, muito alta ou extremamente alta.

Os resultados produzidos servem de subsídios ao planejamento ambiental da área, mostrando as glebas de maior potencial aos riscos ambientais. Mas, vale lembrar que a avaliação da vulnerabilidade ambiental aqui apresentado não considerou as informações geotécnicas dos 
solos e das rochas. No caso especifico da gestão de parcelas do território o estudo necessitaria de detalhamento geológico-geotécnico e pedológico-geotécnico, no sentido de se estabelecer os cuidados especiais na execução de obras civis.

A maior dificuldade observada no uso desta metodologia consiste na atribuição de "pesos" às variáveis selecionadas. Pois, a definição e a atribuição de "pesos" é um fator determinante nos resultados finais, podendo conduzir a resultados variados, ou mesmo divergentes em função desta atribuição.

\section{AGRADECIMENTO}

A fundação de Amparo a Pesquisa do Estado do Rio de Janeiro (FAPERJ)

\section{REFERÊNCIAS}

AGÊNCIA NACIONAL DE ÁGUAS (Brasil). HidroWeb: Sistema de Informações Hidrológicas. 2007. Disponível em: 〈http://www.ana.gov.br〉. Acesso em: 10 jul. 2013.

BATJES, N. H.; BRIDGES, E. M. (Ed.). Implementation of a soil degradation and vulnerability database for Central and Eastern Europeu (SOVEUR Project): proceedings of an international workshop (Wageningen, 1-3 October 1997). Rome: FAO; Wageningen: ISRIC, 2000. $89 \mathrm{p}$.

BECKER, B. K.; EGLER, C.A.G. Detalhamento Metodologia de Execução do Zoneamento Ecológico-Econômico pelos Estados da Amazônia Legal: Brasília, SAEMMA. 1996.

BIGARELlA, J. J.; BECKER, R. D.; PASSOS, E.; CARVALHO, S. M. C. Estruturas e origem das paisagens tropicais e subtropicais. Florianópolis: Ed. da UFSC, 2003. v. 3, p. 877-936.

BIRKMANN, J.; Risk and vulnerability indicators at different scales: applicability usefulness and policy implications. Environ Hazards, v.7, n.1, p.20-31. 2007

CALDERANO FILHO, B. Análise geoambiental de paisagens rurais montanhosas da Serra do Mar utilizando redes neurais artificiais. Subsídios a sustentabilidade ambiental de ecossistemas frágeis e fragmentados sob interferência antrópica. 2012.332 f. Tese (Doutorado em Geologia), - Instituto de Geociências, Universidade Federal do Rio de Janeiro, Rio de Janeiro.

CALDERANO FILHO, B.; POLIVANOV, H.; CHAGAS. C. S.; CARVALHO JÚNIOR, W.; CAlderano. S. B.; guerra, A. J. T.; DONAGEMMA. G. K. Solos do Médio Alto 
Curso do Rio Grande (RJ); Subsídios ao Planejamento de Paisagens Rurais Montanhosas da Serra do Mar. Rio de Janeiro: Embrapa Solos, 2012. (Embrapa Solos. Boletim de Pesquisa e Desenvolvimento, 212).

CREPANI, E.; MEDEIROS, J. S.; HERNANDEZ FILHO, P.; FlORENZANO, T. G.; DUARTE, V.; BARBOSA, C. C. F. (2001). Sensoriamento Remoto e Geoprocessamento Aplicados ao Zoneamento Ecológico-Econômico e ao Ordenamento Territorial. São José dos Campos: INPE. 2001.

DANTAS, M. E.; SHINZATO, E.; MEDINA, A. I. M.; SILVA, C. R. da; PIMENTEL, J.; LUMBRERAS, J. F.; CALDERANO, S. B.; CARVALHO FILHO, A. de. Estudo geoambiental do Estado do Rio de Janeiro. Brasília, DF: CPRM - Serviço Geológico do Brasil, 2000. 1 CD-ROM. (Geomorfologia do Estado do Rio de Janeiro).

EMBRAPA -Empresa Brasileira de Pesquisa Agropecuária. Centro Nacional de Pesquisa de Solos (Rio de Janeiro, RJ). Sistema brasileiro de classificação de solos. Rio de Janeiro: EMBRAPA-SPI. 2006.

ENGEL, B. Estimating Soil Erosion Using RUSLE (Revised Universal Soil Loss Equation) Using ArcView. Purdue University, Department of Agricultural and Biological Engineering, West Lafayette, Indiana. 1999, 10 p.

FAO. Mapping of soil and terrain vulnerability in Central and Eastern Europe: CD of SOVEUR project (Versão.1.0). Rome, 2000.

KOBIYAMA, M.; MENDONÇA, M.; MORENO, D. A.; MARCELINO, I. P. V. O.; MARCELINO, E. V.; GONÇALVES, E. F.; BRAZETTI, L. L. P.; GOERL, R. F.; MOLLERI, G. S. F.; RUDORFF, F. M. Prevenção de desastres naturais: conceitos básicos. Ed. Organic Trading. 2006.

KLEIN R, J. T., NICHOLLS, R. J., RAGOONADEN, S., CAPOBIANCO, M., ASTON, J., BUCKLEY, E. N. Technological options for adaptation to climate change in coastal zones. $\mathbf{J}$ Coastal Res, v.17, p. 532-543. 2001.

KRUIJF, H. A. M.; SCHOUTEN, A. J. On problem of measuring vulnerability of soil ecosystems. In: DUIJVENBOODEN, W. Van, ed. Vulnerability of soil and groundwater polluttants. The Hague: W. Van, 1987. p. 97-109.

LI, A.; WANG, A.; LIANG, S.; ZHOU, W. Eco-environmental vulnerability evaluation in mountainous region using remote sensing and GIS - a case study in the upper reaches of Minjiang River, China. Ecol Model, v. 192, p. 175-187, 2006.

MOURA, A. C. M.; Reflexões metodológicas como subsídios para estudos ambientais 
baseados em análise de multicritérios. Anais XIII Simpósio Brasileiro de Sensoriamento Remoto, Florianópolis, Brasil, 21-26 de abril, p.2889-2906. INPE, 2007.

MATOS, G. M. M. de; FERRARI, P. G.; CAVAlCANTI, J. C. Projeto Faixa Calcária Cordeiro-Cantagalo: relatório final: textos e mapas geológicos. Belo Horizonte: CPRM, 1980.v. 1.

METZGER, M. J.; ROUNSEVELL, M. D. A.; ACOSTA-MICHLIK, L; LEEMANS, R.; SCHOTER, D. The vulnerability of ecosystems services to land use change. Agr, Ecosyst Environ, v. 114, n. 1, p. 69-85, 2006.

SCHOTER, D.; METZGER, M. J.; CRAMER, W.; LEEMANS, R. Vulnerability assessment - analysing the human-environment system in the face of global environmental change. ESS Bulletin, v. 2, n. 2, p. 11-17, 2004.

SPINELLI, M.V.P.; CARVALHO, R.M.C.M.O; SILVA, H.P.; BRANDÃO, S.S.F.; FRUTUOSO, M.N.M.de A. Estudo sustentável da capacidade de carga antrópica e a sua influência no ponto de equilíbrio da resiliência ambiental. Revista Brasileira de Geografia Física v. 09 n. 01, p. 185-199. 2016.

TOMLIN, C.D. Geographic Information systems and cartographic modeling. Englewood Cliffs: Prentice Hall, 249 p., 1990.

VAN WESTEN, C. J. Castellanos, E. Kuriakose, S. L. Spatial data for landslide susceptibility, hazard, and vulnerability assessment: An overview. Eng Geol.Vol. 102. N. 3-4, p.112-131.Dezembro 2008.

ZHONG, C.; HE, Z.; LIU, S. Evaluation of ecoenvironmental stability based on GIS in Tibet, China. Journal of Natural Sciences, v. 10, n. 4, p. 653-658, 2005.

WITTERN, K. P.; MOTCHI, E. P.; CALDERANO FILHO, B.; LEMOS, A. L. Levantamento semidetalhado de solos e avaliação da aptidão agrícola das terras da Usina Novo Horizonte no Município de Campos, RJ. Rio de Janeiro, 1990. 86 p. Relatório técnico. Convênio Secretaria Estadual de Agricultura SEA-RJ/Emater-Rio/Embrapa Solos. 